\title{
Intravenous iron sucrose for treatment of anemia in gynecology patients awaiting surgery
}

\author{
Animesh Gandhi ${ }^{1}$, Meena N. Satia ${ }^{2} *$

\begin{abstract}
${ }^{1}$ Department of Obstetrics and Gynaecology, Topiwala National Medical College andNair Hospital, Mumbai, Maharashtra, India

${ }^{2}$ Department of Obstetrics and Gynaecology, Seth Gordhandas Sunderdas Medical College and King Edward VII Memorial Hospital, Mumbai, Maharashtra, India
\end{abstract}

Received: 27 July 2016

Accepted: 28 August 2016

\section{*Correspondence:}

Dr. Meena N. Satia,

E-mail: meenasatia@kem.edu

Copyright: $\odot$ the author(s), publisher and licensee Medip Academy. This is an open-access article distributed under the terms of the Creative Commons Attribution Non-Commercial License, which permits unrestricted non-commercial use, distribution, and reproduction in any medium, provided the original work is properly cited.

\section{ABSTRACT}

Background: Anemia refers to reduction in the total circulatory erythrocyte mass which results in decrease in the oxygen carrying capacity of the blood. Patients who require a surgical intervention as regards their complaints are many a times denied fitness because of anemia. Current anesthetic and surgical practice ideally recommend a hemoglobin level of $>10 \mathrm{~g} / \mathrm{dl}$ or a hematocrit of $>30 \%$ for any surgical intervention. Surgery is postponed until cause of anemia is identified and the anemia corrected without resorting to blood transfusions. The current study evaluates other alternatives to increase the hemoglobin as early as possible without resorting to blood transfusion. The efficacy and safety of intravenous iron sucrose along with the achievement of the desired hemoglobin values for patients posted for elective gynecological surgeries within the next menstrual cycle was evaluated.

Methods: This study was an open label, single arm, and prospective study of women with iron deficiency anemia in gynecological disorders. 100 patients attending Gynecology OPD of Seth G. S. Medical College and KEM Hospital, Parel, Mumbai, Maharashtra, India requiring surgical intervention but not given fitness due to anaemia were the subjects of this study. All patients with surgically treatable conditions with hemoglobin level $>7 \mathrm{~g} / \mathrm{dL}$ but $<10 \mathrm{~g} / \mathrm{dl}$ were the inclusion criteria Selected subjects received intravenous iron sucrose. Maximum dose 200mg/weekX3 weeks initially. At the end of three weeks of starting therapy $\mathrm{Hb}$ estimation was done and compared with the baseline levels as regarding the hemoglobin rise. The results were statistically analyzed using the "paired t" test.

Results: The requirement of iron-sucrose for the individual patient was calculated based on the weight of the patient. The analysis of iron requirement-sucrose combination showed a mean of $481.7 \mathrm{mg}$ with standard deviation (SD) of $62.72 \mathrm{mg}$ and a range of $378.85 \mathrm{mg}$. The minimum iron-sucrose requirement was $361.55 \mathrm{mg}$ and the maximum was $740.40 \mathrm{mg}$ The mean $\mathrm{Hb}(\mathrm{gm} \%)$ value before intervention was 8.43 with a standard deviation of 0.56 , whereas, the mean $\mathrm{Hb}(\mathrm{gm} \%)$ value after intervention was higher, 10.41 with standard deviation (SD) of .56 the mean $\mathrm{Hb}(\mathrm{gm} \%)$ Increase in 2 weeks was 1.60 with standard deviation (SD) of 0.31 , whereas, in 3 weeks was 2.03 with standard deviation (SD) of 0.51 . The mean $\mathrm{Hb}(\mathrm{gm} \%)$ increase was higher in participants with 3 weeks, which was statistically significant $(\mathrm{p}<0.05)$.

Conclusions: Parenteral iron therapy was not safe in the past but iron sucrose has made it the safest and effective therapy. Parenteral iron therapy can be used for patients with $\mathrm{Hb}$ level between $6-8 \mathrm{mg} / \mathrm{dl}$ It is highly efficacious and reliable way to achieve the desired $\mathrm{Hb}$ level patient compliance is assured with intravenous iron sucrose patient can be satisfactorily posted for surgery within a period of 3 weeks i.e. within her next menstrual period by reliably and effectively correcting her anemia with intravenous iron sucrose.

Keywords: Parenteral Fe therapy, Fe Sucrose, AUB 


\section{INTRODUCTION}

Anaemia is defined as a condition where there is fall in hemoglobin less than $12 \mathrm{mg} / \mathrm{dl}$ along with fall in red cell mass and fall in hematocrit less than 2 SD of the mean as suggested by a WHO expert committee. ${ }^{1}$ In adult females, less than $12 \mathrm{gm} \%$ hemoglobin in peripheral blood is called anemia (WHO). ${ }^{2}$ Most common causes of anemia in gynecology patients are nutritional iron deficiency and blood loss which could be acute or chronic. Anemia due to blood loss is a vicious cycle, every monthly menstrual cycle results in more blood loss and worsening of anemia correction of which therefore has to be fast and effective preferably before they get their next menses especially before any surgical intervention. Occurrence of anemia ranges between $35-100 \%$ among different regions of world. ${ }^{3}$ In developed countries, it is on lesser side and is about $18-20 \%$. Studies of non-pregnant women report prevalence of over $40 \%$ in developing and $10 \%$ in developed countries. Various studies from different regions of the country (India) have reported the prevalence of anemia to be between $33 \%$ and $100 \%$. $^{4,5}$

Prevalence of anemia is high among all Indian women. In all $32.4 \%$ of women had mild anaemia, $14.19 \%$ had moderate and $2.2 \%$ had severe anemia $<70 \mathrm{~g} / \mathrm{l}$. It is less commonly seen high socioeconomic status patients particularly in urban areas. Poor urban women had the highest rates and odds of being anemic various factors are etiologically responsible for anemia. They can be classified as follows:

\section{Classification of anemia according to underlying mechanism: ${ }^{6}$}

Blood loss due to trauma, hookworm infestation /irritable bowel disease, AUB increased rate of destruction like hemolytic anemias and impaired red cell production as in aplastic anemia, pure red cell aplasia, anemia of renal failure, anemia of endocrine disorders. Other causes may be due to disturbance of proliferation and maturation of erythroblasts, defective DNA synthesis: deficiency of vitamin B12 and folic acid, defective hemoglobin synthesis as in thalassemia. Characteristic symptoms of anaemia are fatigue, weakness, lassitude, palpitation, exertional dyspnea. Less common symptoms include dizziness, loss of concentration. Pica also can be seen as one of the symptoms.

Table 1: Differential diagnosis of microcytic, hypochromic anemia.

\begin{tabular}{|c|c|c|c|c|}
\hline & $\begin{array}{l}\text { Iron deficiency } \\
\text { anemia }\end{array}$ & B thalassemia trait & Anemia of chronic disease & $\begin{array}{l}\text { Sideroblastic } \\
\text { anemia }\end{array}$ \\
\hline Serum iron & $\downarrow$ & $\mathrm{N}$ & $\downarrow$ & $\uparrow$ \\
\hline TIBC & $\uparrow$ & $\mathrm{N}$ & $\downarrow$ & $\mathrm{N}$ \\
\hline Serum ferritin & $\downarrow$ & $\mathrm{N}$ & $\uparrow$ & $\uparrow$ \\
\hline Red cell protoporphyrin & $\uparrow$ & $\mathrm{N}$ & $\uparrow$ & $\uparrow$ or $\mathrm{N}$ \\
\hline $\mathrm{HbA}_{2}$ & $\downarrow$ & $\uparrow$ & $\mathrm{N}$ & $\downarrow$ \\
\hline
\end{tabular}

\section{Therapeutic options}

\section{Oral iron therapy}

Multiple oral iron preparations are available. Ferrous salts are better absorbed than ferric salts. Ferric forms must be first reduced to ferrous form before they are absorbed by duodenum. Ferrous salts are unstable in solution as they get oxidized to ferric form and become inactive. Ferrous salts are best given as capsules, which are sustained release preparations. They are formulated for slower release of iron as the capsule passes through the gastrointestinal tract. This avoids increased concentration at one site. It further reduces the irritation of gastrointestinal mucosa. Hence, compliance with slow release preparation is more than old preparations Response is adequate with oral iron therapy in patients with IDA as absorption is good. However, parenteral therapy is indicated in a small proportion of cases. The pattern of response to parenteral therapy is similar to that with oral iron.

\section{Indications}

\section{Indications of parenteral therapy}

- Intolerance to oral iron.

- Non-compliance to oral iron.

- Poor absorption of oral iron (malabsorption syndrome, dysentery etc).

- No response to oral iron after 4 weeks in confirmed case of iron deficiency anemia.

- Chronic blood loss.

- Gastrointestinal disorders whose symptoms may be aggravated by oral iron (viz. peptic ulcer disease, ulcerative colitis etc). 
When rapid replenishment of iron stores is required as seen in severe anemia discovered late in pregnancy or in preparation for surgery, parenteral iron may be used as preferable and confirmed predictable alternative.

\section{Contraindications $^{7}$}

Parenteral preparations are available but are contraindicated in patients with a history of allergy and in those who had a previous serious reaction to the preparation.

\section{Parenteral iron preparations}

- Iron dextran

- Low molecular weight iron dextran

- Sodium ferric gluconate complex (SFGC)

- Iron sucrose

With iron dextran and iron sorbitol-citrate complex preparation-following adverse reactions can occur. ${ }^{8}$

Local reaction: Staining of skin, pain and abscess formation.

Systemi: Pyrexia, myalgia, arthralgia and lymphadenopathy severe anaphylactic reaction may occur sometimes. ${ }^{9}$ Before giving these preparations complete emergency kit has to be in place due to unforeseen anaphylactic reactions. These are characterized by rigors, chest pain, fever, dyspnea, flushing, sweating, nausea, vomiting. The infusion should be immediately stopped and adrenalin, antihistaminics and hydrocortisone should be immediately administered. Resuscitative measures are to be employed. Some patients experience, unpleasant taste following the use of iron sorbitol citrate.

Because of all these adverse reactions, IV or IM instillation of iron was thought to be risky and inconvenient but after introduction of molecule iron sucrose, all these worries seem to be negligible. Iron sucrose is a complex hydroxide with cores which are superficially surrounded by a large number of sucrose molecules which are not covalently bound resulting in a complex with a molecular weight of approximately 60,000 daltons in sucrose for intravenous use. ${ }^{10}$ The iron in the polynuclear cores is comparable to that of physiologically occurring ferritin. The complex is stable and does not disintegrate to liberate ionic iron under physiological conditions. Following intravenous administration, iron sucrose is disintegrated by the RE system into iron and sucrose. Slow intravenous injection $100 \mathrm{mg}$ of Fe Sucrose diluted in $100 \mathrm{ml}$ of NS is given at a rate of $1 \mathrm{ml}$ (20mg iron) solution per minute not exceeding $100 \mathrm{mg}$ iron per injection. The solution must be infused at a rate of $100 \mathrm{mg} / 15$ minutes.

It is recommended that total required dose of iron should be administered as 100-200/week for 3 weeks. Thus the required iron can be given at a speed not more than $600 \mathrm{mg}$ per week.

\section{Advantages over iron dextran}

- Test dose is required for iron dextran and LMW iron dextran but test dose is not required for iron sucrose.

- Iron sucrose does not contain dextran hence the chances of allergic reactions and anaphylaxis are negligible with iron sucrose

- Release of iron from the complex is very slow for iron dextran as compared to iron sucrose.

- Plasma half-life of iron dextran is 3-4 days while that of iron sucrose is 6 hours. Hence iron from iron sucrose is more rapidly available for erythropoiesis than iron from iron dextran. As a result, iron sucrose produces more rapid increase in hemoglobin than iron dextran.

- Iron dextran is in pregnancy category $\mathrm{C}$ while iron sucrose is in pregnancy category B.

\section{Advantages over sodium ferric gluconate complex}

- Large amount of iron from SFGC enters the liver parenchyma than from iron sucrose. As a result the chances of free radical induced liver toxicity are more with SFGC than with iron sucrose.

- Clinical studies have found that iron sucrose is well tolerated in patients with previously documented intolerance to SFGC.

Due to this safe administration technique, management of iron deficiency anemia is easy avoiding hazards associated with blood transfusion. ${ }^{11,12}$

\section{Contraindications of iron sucrose}

- Evidence of iron overload

- Known hypersensitivity to the product

\section{Response}

Adequate replenishment is followed by an increase in the reticulocyte count. This usually begins by the $4^{\text {th }}$ day and last for about 12 days. The response is inversely proportional to $\mathrm{Hb}$ level before treatment. It is more practical to use the rise in $\mathrm{Hb}$ level as a measure of effectivity of therapy. The $\mathrm{Hb}$ level rises at an average rate of about $0.15 \mathrm{gm} / \mathrm{dL}$ per day, usually commencing about one week after therapy is begun. The aim of the study was to study efficacy of intravenous iron sucrose in gynecology patients awaiting surgery.

\section{Objectives}

- To study rise in hemoglobin in gynecology patients with intravenous iron sucrose over a period of three weeks. 
- $\quad$ To ascertain the time period required for the patients to get fitness based on raised hemoglobin levels.

\section{METHODS}

This study was open label, single arm, and prospective study of women with iron deficiency anemia in gynecological disorders managed on outdoor/indoor basis over a period of one year after IEC approval. 100 patients attending gynecology OPD requiring surgical intervention but not given fitness due to reasons of low hemoglobin levels were selected as the subjects of this study. Patients having excessive bleeding per vagina due to surgically treatable condition like fibroid, menorrhagia, DUB, polypoidal endometrium, were the main subjects of the study. The patients included were those requiring either minor or major gynaecological surgery.

\section{Inclusion criteria}

Patients with surgically treatable condition with hemoglobin level $>7 \mathrm{~g} / \mathrm{dL}$ but $<10 \mathrm{~g} / \mathrm{dl}$ giving consent for this study.

\section{Exclusion criteria}

Pregnancy, macrocytic anaemia, underlying diseases like hypertension, diabetes mellitus, heart disease, peptic ulcer, allergy to iron containing preparation, history of allergic conditions or asthma, hematologic disorders like thalassemia.

Baseline investigations done in each subject on OPD basis were as follows:

- Hemoglobin levels, complete blood counts : these would help to select the subjects and to exclude those that have signs of infection, allergies.

- $\mathrm{Hb}$ Electrophoresis to rule out hematologic conditions like sickle cell and thalassemia.

- Peripheral smear for RBC morphology will help to ascertain that anemia is indeed due to blood loss and iron deficiency and to exclude macrocytic anemias.
- Stool examination routine and microscopy for parasites and occult blood.

- Urine examination routine and microscopy and pregnancy test.

Based on the above investigations the subject and the questionnaire subject would be selected as fit for the study or not.

Selected subjects were admitted to the hospital and received intravenous iron sucrose as per dose requirement calculated as: hemoglobin deficit $\mathrm{x}$ body weight in $\mathrm{kg} \mathrm{x}$ $0.3+10 \mathrm{mg} / \mathrm{kg}$ (which is required to replenish stores). ${ }^{10}$ Maximum dose $200 \mathrm{mg}$ /week given for 2 weeks initially. The preparation used was iron sucrose. 1 ampoule contains $2.5 \mathrm{~mL}$ solution with $20 \mathrm{mg} / \mathrm{mL}$ i.e. $50 \mathrm{mg} /$ ampoule. 2 ampoules of iron sucrose i.e. $100 \mathrm{mg}$ in $100 \mathrm{~mL}$ NS over a period of 30 minutes and the dose repeated again after 48 hours. Thus $200 \mathrm{mg}$ would be given in a week and then patient would be called again the next week for similar infusion. If the dose exceeds $400 \mathrm{mg}$ then patient will be called again in the third week, his hemoglobin checked and if still below $10 \mathrm{~g} / \mathrm{dL}$ he would be given another infusion. The subjects would be discharged and asked to follow up at the end of two weeks and at the end of three weeks of starting therapy and blood samples would be collected again and compared with the baseline levels as regarding the hemoglobin rise. The results would be statistically analyzed using the "paired t" test.

\section{RESULTS}

The mean age of the participant was 45.25 years with a standard deviation (SD) of 10.34 years. The minimum age of the participant was 24 years and the maximum was 75 years. Age group 40-50 years was the commonest with $50 \%$ of the total frequency, followed by, 30-40 years (22\%).The minimum weight of the participant was $35 \mathrm{Kg}$ and the maximum was $68 \mathrm{Kg}$. The mean weight was $45.72 \mathrm{Kg}$ with standard deviation (SD) of $5.42 \mathrm{Kg}$. The weight of the participant was taken for calculating the dose of the iron-sucrose combination required for the individual participant.

Table 2: Fe requirement.

\begin{tabular}{|llllllll|}
\hline $\begin{array}{l}\text { Requirement of } \\
\text { iron sucrose }(\mathrm{mg})\end{array}$ & 100 & 378.85 & 361.55 & 740.40 & 481.7 & 62.72 & 378.85 \\
\hline
\end{tabular}

The requirement of iron-sucrose for the individual patient was calculated based on the weight of the same patient. The analysis of requirement of iron sucrose combination showed a mean of $481.7 \mathrm{mg}$ with standard deviation (SD) of $62.72 \mathrm{mg}$ and a range of $378.85 \mathrm{mg}$. The minimum iron- sucrose requirement was $361.55 \mathrm{mg}$ and the maximum was $740.40 \mathrm{mg}$. The mean $\mathrm{Hb}(\mathrm{gm} \%$ ) value before intervention was 8.43 with a standard deviation of 0.56 , whereas, the mean $\mathrm{Hb}(\mathrm{gm} \%)$ value after intervention was higher, 10.41 with standard deviation (SD) of 0.56 . 
Paired t test was done to find whether the difference in mean $\mathrm{Hb}(\mathrm{gm} \mathrm{\%})$ in before and after intervention was statistically significant, the test was statistically significant ( $\mathrm{p}<0.05)$. The mean $\mathrm{Hb}(\mathrm{gm} \%)$ Increase due to the intervention seen in our participants was 1.98 with standard deviation (SD) of 0.51. The minimum $\mathrm{Hb}$ (gm\%) Increase was 0.90 and the maximum was 3.60.

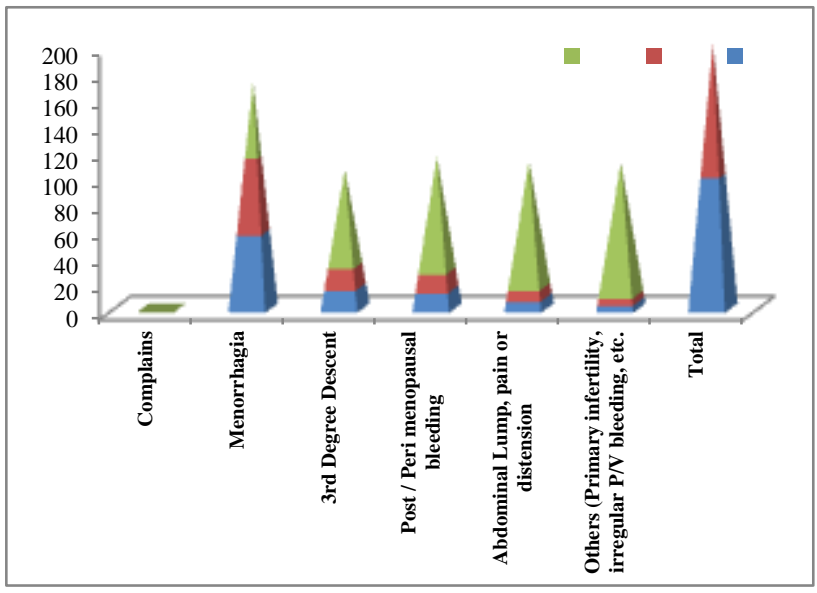

Figure 1: Clinical symptoms.

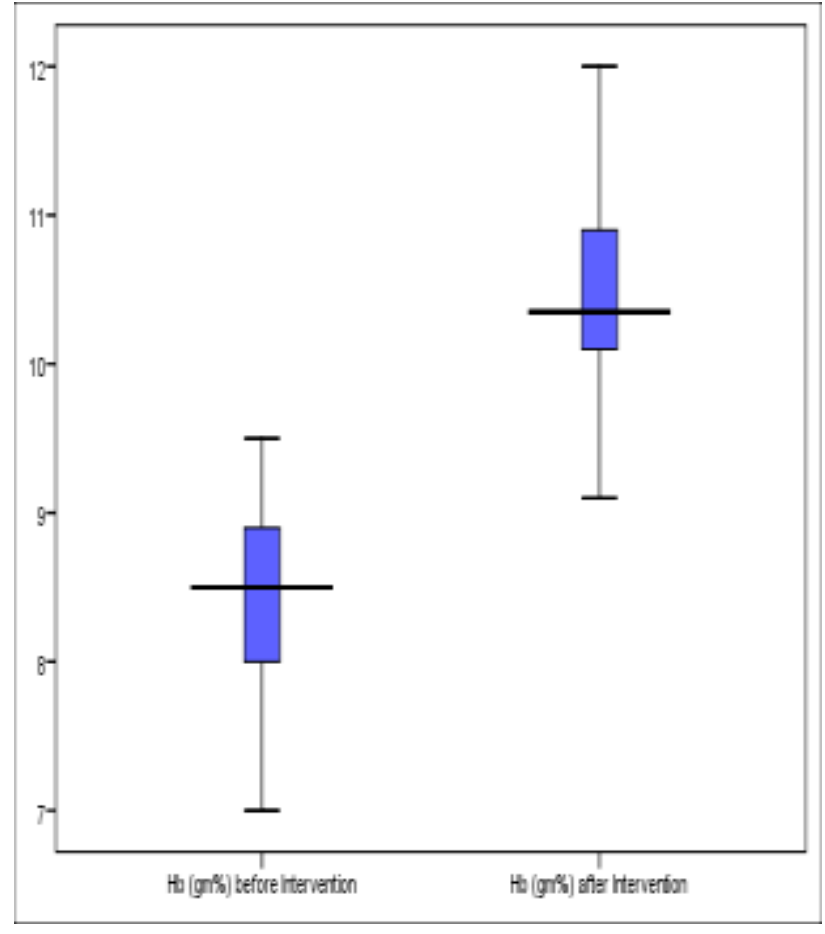

Figure 2: Paired t test.

Table 3: Hb gm\% before and after intervention.

\begin{tabular}{|lccccccc|}
\hline & $\mathrm{N}$ & Range & Minimum & Maximum & Mean & Std. deviation & Variance \\
\hline $\begin{array}{l}\mathrm{Hb}(\mathrm{gm} \%) \text { before } \\
\text { intervention }\end{array}$ & 100 & 2.50 & 7.00 & 9.50 & 8.43 & 0.56 & 0.317 \\
\hline $\begin{array}{l}\mathrm{Hb}(\mathrm{gm} \%) \text { after } \\
\text { intervention }\end{array}$ & 100 & 2.90 & 9.10 & 12.00 & 10.41 & 0.56 & 0.314 \\
\hline
\end{tabular}

Table 4: Paired samples test.

\begin{tabular}{|c|c|c|c|c|c|c|}
\hline & \multicolumn{3}{|c|}{ Paired differences } & \multirow{2}{*}{$\mathrm{t}$} & \multirow{2}{*}{ df } & \multirow{2}{*}{ Sig. (2-tailed) } \\
\hline & Mean & Std. deviation & Std. error mean & & & \\
\hline $\begin{array}{l}\mathrm{Hb}(\mathrm{gm} \%) \text { before Intervention - } \\
\mathrm{Hb}(\mathrm{gm} \%) \text { after Intervention }\end{array}$ & -1.98 & .51 & .051 & -38.39 & 99 & .000 \\
\hline
\end{tabular}

Table 5: Hb (gm \%) increase due to intervention.

\begin{tabular}{|llllllll|}
\hline & $\mathrm{N}$ & Range & Minimum & Maximum & Mean & Std. deviation & Variance \\
\hline $\mathrm{Hb}(\mathrm{gm} \%)$ increase & 100 & 2.70 & 0.90 & 3.60 & 1.98 & 0.51 & 0.26 \\
\hline
\end{tabular}

Table 6: $\mathrm{Hb}$ (gm \%) increase in 2 and 3 weeks.

\begin{tabular}{|llllll|}
\hline & Weeks after intervention & $\mathbf{N}$ & Mean & $\begin{array}{l}\text { Std. } \\
\text { deviation }\end{array}$ & $\begin{array}{l}\text { Std. error } \\
\text { mean }\end{array}$ \\
\hline $\begin{array}{l}\text { Increase in } \mathrm{Hb}(\mathrm{gm} \%) \text { due to } \\
\text { intervention }\end{array}$ & $\mathrm{Hb}(\mathrm{gm} \%)$ after 2 weeks & 12 & 1.6000 & 0.31 & .09129 \\
\cline { 2 - 7 } & $\mathrm{Hb}(\mathrm{gm} \%)$ after 3 weeks & 88 & 2.0330 & 0.51 & .05514 \\
\hline
\end{tabular}


The mean $\mathrm{Hb}$ (gm \%) increase in 2 weeks was 1.60 with standard deviation (SD) of 0.31 , whereas, in 3 weeks was 2.03 with standard deviation (SD) of 0.51 .

The mean $\mathrm{Hb}$ (gm \%) Increase was higher in participants with 3 weeks, which was statistically significant ( $p$ $<0.05)$.

The mean difference (or increase) in $\mathrm{Hb}(\mathrm{gm} \%)$ in participants with dose of Iron-Sucrose $400 \mathrm{mg}$ was 1.92 , whereas, in participants with dose of Iron-Sucrose 600 mg was 2.47 .

Hence, the mean increase was higher in participants with higher dose of iron-sucrose; it was statistically significant $(\mathrm{p}<0.05)$.

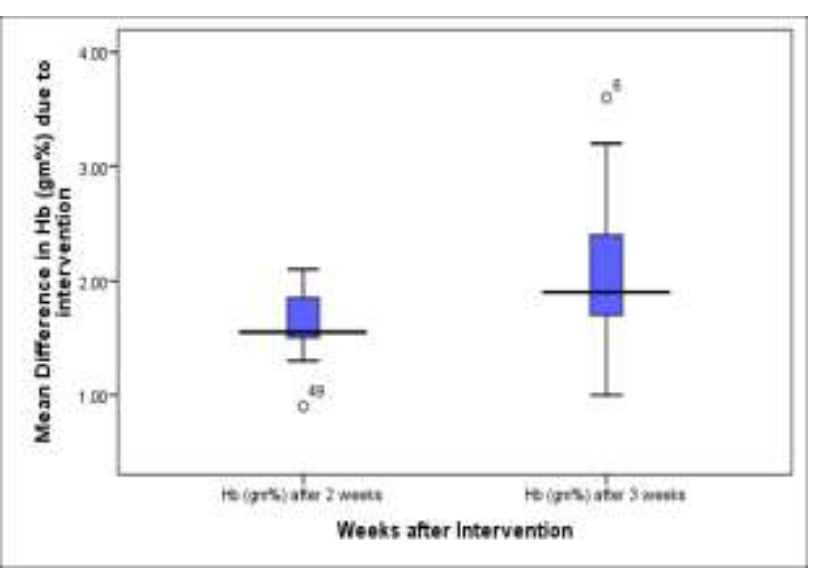

Figure 3: Rise in hemoglobin after 2 and 3 weeks.

\section{DISCUSSION}

Approximately one fourth of the global population is suffering from iron deficiency anemia. ${ }^{13,14}$ Oral iron therapy because of its effectiveness, safety and low cost is the best modality of treatment of iron deficiency anemia. Due to noncompliance on the part of patients its efficacy is limited in many patients because of the side effects related to the drug, particularly gastrointestinal disturbances occurring in $50 \%$ of patients and the long course needed to treat anemia and replenish iron stores. ${ }^{15,16}$ Non-compliance to oral iron is common and, even in compliant patients, because of poor absorption iron therapy still is required in the patients with AUB or with chronic blood loss. ${ }^{15,16}$

While intravenous (IV) iron by passes these problems, fear remains about its harmful effects and the potential for long-term hazards from multiple doses of iron administration. ${ }^{17,18}$

Parenteral iron preparations which were available in the olden days were associated with dangerous complications like anaphylactic reactions and death, due to which they have gone in disrepute. ${ }^{19}$ The high-molecular-weight iron dextran formulation most frequently were responsible for these side effects seen in $2.3 \%$ of the patients. ${ }^{20,21}$ However, the availability of new preparations like iron sucrose, with much better safety profiles, are more useful in day to day clinical practice. ${ }^{17,22}$

The present study was done to evaluate the safety and the effectiveness of IV iron sucrose for pre-op patients waiting for fitness prior to surgery.

\section{Age comparison}

The study reveals that anemia in non-pregnant gynecology women are seen most commonly in age group of $40-50$ years $(50 \%) .72 \%$ of patients are in age group 30-50 years.

Levy TS et al, in their study showed that the prevalence of anemia increased with age. ${ }^{23}$ Present study shows anemia to be more prevalent in women complaining of menorrhagia $(57 \%)$, and in uterovaginal prolapse $(16 \%)$.

Table 7: Comparative statistics.

\begin{tabular}{|lccccc|}
\hline & AUB & Fibroid & Polyp & Prolapse & Anaemia \\
\hline Younis N et al & 24 & & & $56 \%$ & $63 \%$ \\
\hline Vercellini $\mathrm{P}^{25}$ & & $38 \%$ & $13 \%$ & & $67 \%$ \\
\hline Present study & $25 \%$ & $18 \%$ & $11 \%$ & $16 \%$ & $57 \%$ \\
\hline
\end{tabular}

Table 8: Comparative statistics.

\begin{tabular}{|c|c|c|c|c|}
\hline Study & No of patients & Hb increase & Ferritin level rise & P value \\
\hline Kim YH et al, IV vs oral ${ }^{26}$ & 76 & $3 \mathrm{gm} \%$ & 170.1 vs. $4.1 \mu \mathrm{g} / \mathrm{l}$ & 0.0001 \\
\hline Muñoz $\mathrm{M}$ et $\mathrm{al}^{27}$ & 84 & $1.6 \mathrm{~g} / \mathrm{dl}$ & & $\mathrm{p}<0.001$ \\
\hline 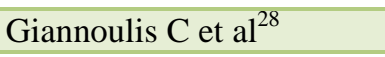 & 104 & $4.6 \mathrm{gr} / \mathrm{dl}$ & $105 \mathrm{mg} / \mathrm{L}$ & $\mathrm{p}=0.0004$ \\
\hline Present study & 100 & 2.0330 & & $\mathrm{p}<0.05$ \\
\hline
\end{tabular}




\section{Mean comparison of pre and post-treatment $\mathrm{Hb}$}

The mean $\mathrm{Hb}(\mathrm{g} \%$ ) value before intervention was 8.43 with a standard deviation of 0.56 , whereas, the mean $\mathrm{Hb}$ (g \%) value after intervention was higher, 10.41 with standard deviation (SD) of 0.56. Paired t-test was done to find whether the difference in mean $\mathrm{Hb}(\mathrm{g} \%)$ in before and after intervention was statistically significant, the test was statistically significant $(\mathrm{p}<0.05)$. The mean $\mathrm{Hb}(\mathrm{g} \%)$ increase due to the intervention seen in our participants was 1.98 with standard deviation (SD) of 0.51 . The minimum $\mathrm{Hb}(\mathrm{g} \%)$ increase was 0.90 and the maximum was 3.60 .

The mean $\mathrm{Hb}(\mathrm{gm} \%)$ increase in 2 weeks was 1.60 with standard deviation (SD) of 0.31 , whereas, in 3 weeks was 2.03 with standard deviation (SD) of 0.51 . The mean $\mathrm{Hb}$ (gm \%) increase was higher in participants with 3 weeks, which was statistically significant $(\mathrm{p}<0.05)$. Thus it is proved that satisfactory rise in hemoglobin can be achieved in a period of 2 to 3 weeks. This makes it possible to operate on the patients before the advent of her next menstrual cycle thus preventing further blood loss and worsening of her anemia. Thus the rise in hemoglobin due to intravenous iron sucrose is evident and proven statistically.

Dangsuwan $\mathrm{P}$ et al compared the incidence of repeated red blood cell (RBC) transfusion in 44 anemic gynecologic cancer patients comparing intravenous and oral iron. They found significantly higher hemoglobin levels after treatment were reported in the study group receiving intravenous iron sucrose $(10.0 \pm 0.8 \mathrm{~g} / \mathrm{dl}$ and $30.5 \pm 2.4 \%$ ) than the control group receiving oral ferrous sulphate $(9.5 \pm 0.9 \mathrm{~g} / \mathrm{dl}$ and $28.4 \pm 2.7 \%)$. They concluded that intravenous iron is a good option for treatment of anemia in gynecologic cancer patients receiving chemotherapy and reduces the incidence of blood transfusion. $^{29}$

Dede A et al, studied and compared the safety profile of intravenous iron sucrose complex and oral ferrous sulfate in the treatment anemia in the post natal period in 75 patients. They concluded that compared to oral ferrous sulfate, IV iron therapy with an iron sucrose increased serum ferritin level within a short time with fewer adverse effects in women with postpartum iron deficiency anemia. The difference in $\mathrm{Hb}$ between the two groups was not significant. ${ }^{30}$

\section{CONCLUSION}

In the current study, 100 patients received intravenous iron sucrose for treatment of their anemia as per requirement based on the weight and hemoglobin deficit of the patient. Age group 40-50 years was the commonest amongst the patients with $50 \%$ of the total frequency, followed by $30-40$ years $(22 \%)$. The most common complaint of the participants studied was menorrhagia (57\%), followed by 3rd degree descent (16\%) and post/peri menopausal bleeding (14\%). The most common clinical finding in the study participant was DUB/AUB (37\%), followed by fibroid uterus $(18 \%)$ and prolapse (16\%). Ca Ovary / Ca Endometrium or Ca Cervix was seen in total 8 cases. Ovarian cyst and tender bulky uterus was present in $5 \%$ of the total cases each. The most common histopathological finding in the study participants was benign endometrial pathology (52\%), followed by leiomyoma (20\%), malignant pathology $(8 \%)$, adenomyosis $(6 \%)$, benign endometrial pathology and a polyp (6\%), ovarian tumors (5\%) and a polyp in (3\%). The mean $\mathrm{Hb}(\mathrm{gm} \%)$ value before intervention was 8.43 with a standard deviation of 0.56 , whereas, the mean $\mathrm{Hb}(\mathrm{gm} \%)$ value after intervention was higher, 10.41 with standard deviation (SD) of (0.56). The difference in mean $\mathrm{Hb}(\mathrm{gm} \mathrm{\%})$ in before and after intervention was statistically significant. ( $\mathrm{p}<0.05)$. The mean $\mathrm{Hb}(\mathrm{gm} \%)$ increase due to the intervention seen in our participants was 1.98 with standard deviation (SD) of 0.51 . The minimum $\mathrm{Hb}(\mathrm{gm} \mathrm{\%})$ increase was 0.90 and the maximum was 3.60. The mean $\mathrm{Hb}(\mathrm{gm} \%)$ increase in 2 weeks was 1.60 with standard deviation (SD) of 0.31 , whereas, in 3 weeks was 2.03 with standard deviation (SD) of 0.51 . The mean $\mathrm{Hb}$ (gm \%) Increase was higher in participants with 3 weeks, which was statistically significant $(\mathrm{p}<0.05)$.

The mean difference (or increase) in $\mathrm{Hb}$ (gm\%) in participants with dose of Iron-Sucrose $400 \mathrm{mg}$ was 1.92 , whereas, in participants with dose of iron-sucrose $600 \mathrm{mg}$ was 2.47. Hence, the mean increase was higher in participants with higher dose of Iron-Sucrose; it was statistically significant $(\mathrm{p}<0.05)$.

Thus, iron sucrose is a complex of polynuclear iron (III) hydroxide in sucrose for intravenous use. Moderate to severe anemia can be treated by various routes of administration of iron like oral and parenteral route. Parenteral iron therapy was not safe in the past but iron sucrose has made it the safest and effective therapy. IV iron sucrose is highly efficacious and reliable way to obtain the rise of $\mathrm{Hb}$ level. Compliance of patient is assured with intravenous iron sucrose patient can be satisfactorily posted for surgery within a period of 3 weeks i.e. within her next menstrual period by reliably and effectively correcting her anemia with intravenous iron sucrose.

Funding: No funding sources

Conflict of interest: None declared

Ethical approval: The study was approved by the Institutional Ethics Committee

\section{REFERENCES}

1. Blanc B, Finch CA, Hallberg L. Nutritional anemia. Report of a WHO Scientific Group. WHO Tech Rep Ser. 1968;405:1-40. 
2. Beutler E, Waalen J. The definition of anemia: what is the lower limit of normal of the blood hemoglobin concentration? Blood. 2006;107(5):1747-50.

3. World Health Organization. The prevalence of anemia in women: a tabulation of available information, 2nd edition, Geneva: WHO. 1992.

4. Luwang NC, Gupta VM, Khanna S. Anemia in pregnancy in a rural community of Varanasi. Indian Journal of Preventive Social Medicine. 1980;11:838.

5. Agarwal V, Tejawani S. Prevalence of iron deficiency anemia in Indian antenatal women especially in rural areas. Indian Medical Gazette. 1999;10:300-3.

6. Kumar V, Aster JC. Red blood cell and bleeding disorders. In Robbins and Cotran. Pathologic basis of disease, 7th edition; Elsevier. 2015:621.

7. Auerbach M, Rodgers GM. Intravenous iron. N Engl J Med. 2007;357:93.

8. Chertow GM, Mason PD, Nilsen VO, Ahlmen J. Update on adverse drug events associated with parenteral iron. Nephrol Dial Transplant. 2006;21:378.

9. Bailie GR, Clark JA, Lane CE, Lane PL. Hypersensitivity reactions and deaths associated with intravenous iron preparations. Nephrol Dial Transplant. 2005;20:1443-9.

10. Momen A, Meshari A, Nuaim L, Saddique A, Abotalib Z, Khashogji T, Abbas M. Intravenous iron sucrose complex in the treatment of iron deficiency anemia during pregnancy. Eur J Obstet Gynecol Reprod Biol. 1996;69:121-4.

11. Hallak M, Sharon AS, Diukman R, Auslender R, Abramovici H. Supplementing iron intravenously in pregnancy, a way to avoid blood transfusion. J Reprod Med. 1997;42:99-103.

12. Auerbach M, Goodnough LT, Picard D, Maniatis A. The role of intravenous iron in anemia management and transfusion avoidance. Transfusion. 2008;48:988.

13. World Health Organization iron deficiency anemia. Assessment, prevention and control. A guide for programme managers. Geneva: WHO; 2001. Available at http: //www.who.int /nutrition /publications/en/ida_assessment_prevention_control. pdf. Accessed on 10 January 2016.

14. World Health Organization. The World Health Report 2002. Reducing risks, promoting healthy life. Geneva: World Health Organization: 2002:1-248.

15. Alleyne M, Horne MK, Miller JL. Individualized treatment for iron-deficiency anemia in adults. Am J Med. 2008;121(11):943-8.

16. Cançado RD, Lobo C, Friedrich JR. Tratamento da anemia ferropriva com ferro via oral. Rev Bras Hematol Hemoter. 2010;32(2):114-20.
17. Auerbach M, Ballard H. Clinical use of intravenous iron: administration, efficacy and safety. Hematology Am Soc Hematol Educ Program. 2010:338-47.

18. Cançado RD, Lobo C, Friedrich JR. Tratamento da anemia ferropriva com ferro via parenteral. Rev Bras Hematol Hemoter. 2010;32(2):121-8.

19. Cançado RD, Figueiredo PON, Olivato MCA, Chiattone CS. Efficacy and safety of intravenous iron sucrose in treating adults with iron deficiency anemia. Rev Bras Hematol Hemoter. 2011;33(6):439-43.

20. Fishbane S, Kowalski EA. The comparative safety of intravenous iron dextran, iron saccharate, and sodium ferric gluconate. Semin Dial. 2000;13(6):381-4.

21. Chertow GM, Mason PD, Nilsen VO, Ahlmen J. Update on adverse drug events associated with parenteral iron. Nephrol Dial Transplant. 2006;21(2):378-82.

22. Auerbach M, Ballard H, Glaspy J. Clinical update: intravenous iron for anaemia. Lancet. 2007;369(9572):1502-4.

23. Levy TS, Hernández VS, Guerra GA, Rosas MV, Rodríguez MF, Islas CP. Anemia in Mexican women: results of two national probabilistic surveys. Salud Publica Mex. 2009;51(4):515-2.

24. Younis N, Khattab H, Zurayk H, Mouelhy M, Amin MF, Farag AM. A community study of gynecological and related morbidities in rural Egypt. Stud Fam Plann. 1993;24(3):175-86.

25. Vercellini P, Vendola N, Ragni G, Trespidi L, Oldani S, Crosignani PG. Abnormal uterine bleeding associated with iron-deficiency anemia. Etiology and role of hysteroscopy. J Reprod Med. 1993;38(7):5024.

26. Kim YH, Chung HH, Kang SB, Kim SB, KimYT. Safety and usefulness of intravenous iron sucrose in the management of preoperative anemia in patients with menorrhagia: a phase iv, open-label, prospective, randomized study. Acta Haematol. 2009;121:37-41.

27. Munoz M, Garcia JA, Diez LAI, Campos A, Sebastianes C, Bisbe E. Usefulness of the administration of intravenous iron sucrose for the correction of preoperative anemia in major surgery patients. Med Clin (Barc). 2009;132(8):303-6.

28. Giannoulis C, Daniilidis A, Tantanasis T, Dinas K, Tzafettas J. Intravenous administration of iron sucrose for treating anemia in postpartum women. Hippokratia. 2009;13(1):38-40.

29. Dangsuwan P, Manchana T. Blood transfusion reduction with intravenous iron in gynecologic cancer patients receiving chemotherapy. Gynecol Oncol. 2010;116(3):522-5.

30. Dede A, Uygur D, Yilmaz B, Mungan T, Ugur M. Intravenous iron sucrose complex vs. oral ferrous sulfate for postpartum iron deficiency anemia. Int J Gynecol Obst. 2005;90:238-9.

Cite this article as: Gandhi A, Satia MN.

Intravenous iron sucrose for treatment of anemia in gynecology patients awaiting surgery. Int J Reprod Contracept Obstet Gynecol 2016;5:3453-60. 